\title{
Factors related to the dental caries incidence in youth: a cohort study in Brazilian Northeastern
}

\author{
Fatores relacionados com a incidência de cárie em jovens: \\ um estudo de coorte no nordeste brasileiro
}

Ana Karine Macedo Teixeira ${ }^{1}$

Angelo Giuseppe Roncalli ${ }^{2}$

Luiz Roberto Augusto Noro ${ }^{2}$

${ }^{1}$ Departamento de Clínica

Abstract The conceptual model of the life course considers that health-disease is a dynamic process that is also affected by previous and current lifelong experiences. The aim of the study was to investigate the incidence of caries and its determinants in young people in Sobral-Ceará, Brazil. This was a cohort study of oral health started in 2000, with waves in 2006 and 2012. 482 young people aged 17-21 years were examined and interviewed. The incidence of caries between 2006 and 2012 was the outcome analyzed and the independent variables were socioeconomic conditions and use of oral health actions and services. The average incidence of caries was 2.95 teeth from the adolescence to the youth. It was found that social deprivation throughout life and deny access to the dentist during infancy implies a greater incidence of caries in youth, therefore, the use of services and oral health actions during the adolescence and youth have not been sufficient to reduce inequities in oral health.

Key words Dental caries, Risk factors, Health inequalities
Resumo O modelo conceitual do life course considera que a saúde-doença é um processo dinâmico afetado por experiências prévias e ao longo da vida. O objetivo do estudo foi investigar a incidência de cárie e seus fatores determinantes em jovens no município de Sobral (CE). Estudo de coorte em saúde bucal iniciado no ano 2000, com ondas em 2006 e em 2012. Foram examinados e entrevistados 482 jovens na faixa etária de 17 a 21 anos. A incidência de cárie entre 2006 e 2012 foi o desfecho analisado e as variáveis independentes foram as condições socioeconômicas e de utilização de ações e serviços de saúde bucal. A incidência média de cárie foi de 2,95 dentes da adolescência para a juventude. Constatou-se que maior privação social ao longo da vida e negar o acesso ao dentista na infância implicam em maior incidência de cárie na juventude, entretanto o uso dos serviços odontológicos na adolescência e na juventude não foi suficiente para reduzir as iniquidades em saúde bucal.

Palavras-chave Cárie dentária, Fatores de risco, Desigualdades em saúde dontologica, Universidade Federal do Ceará. R. Alexandre Baraúna 949, Rodolfo Teófilo. 60430160 Fortaleza CE Brasil. anakarinemt@hotmail.com ${ }^{2}$ Departmento de Odontologia, Universidade Federal do Rio Grande do Norte. Natal RN Brasil. 


\section{Introduction}

The reduction of dental caries has been observed in recent years in Brazil, especially among children and adolescents. However, the disease is still one of the most prevalent, especially in the Northeastern region of the country. According to the results of the SB Brazil 2003 and 2010 in relation to caries, the Northeastern is still worse off than other regions of the country ${ }^{1,2}$.

Currently, decay is assuming polarizing behavior where the greatest burden of illness is concentrated on a minority which reveals the presence of oral health inequities ${ }^{3,4}$. Health inequities are unnecessary and avoidable as it characterized as differences in health status due to some degree of injustice because they are associated with social characteristics that systematically put disadvantaged groups regarding the opportunity to be and stay $^{5}$. Authors have suggested investigating the determinants of health inequities, such as social status, race, and gender, which in turn relate to the use of health services ${ }^{6,7}$.

The life course approach considers that health-disease is a dynamic process that is also affected by previous and current lifelong experiences. The current status of an individual as well as their inequities reflects exposure to different biopsychosocial risk factors during pregnancy, childhood, adolescence, young adults and adult phase $^{8}$, which reveals the need to develop longitudinal studies. However, there are few studies that analyze the dental health changes over time as cohort studies ${ }^{9-12}$.

Studies show that from childhood to adolescence and into adulthood, there is an increase in the prevalence of dental caries. In Brazil, the DMFT (Decayed Missing Filled Teeth) was found to be 2.07 for 12 year olds, it was 4.25 in the age group of 15-19 years and in adulthood it increased to 16.75 , which shows the cumulative effect of the decay over the life of the individual ${ }^{2}$. Understanding which factors are associated with the incidence of dental caries throughout life is still a challenge.

In Sobral, Ceará, located in Brazilian Northeastern, a transversal study was conducted during 2000 to measure the prevalence of caries, malocclusion and gingival bleeding in 1021 children aged 5-9. It was observed that the DMFT increased with age from 0.10 to 1.66 for five to nine year olds. On the other hand, the reverse occurred for the dmft index, 3.59 at 5 years to 2.69 nine years. It was also found that only $23 \%$ of children aged five years were caries free. Re- garding gingival changes, on average $32.7 \%$ of children had gingival bleeding and $60.33 \%$ of the children showed no occlusal problem ${ }^{13}$.

In 2006, following on from the first study in the same county, an epidemiological study of tooth decay incidence was conducted with adolescents 11-15 years old, the same people who participated in the study in 2000, and found an average incidence of 1.86 decayed teeth per teenager and that regular access to a basic health unit indicates lower risk of high caries incidence, while the toothache and consume frequently school meal variables showed a high risk for the incidence of decay ${ }^{14}$.

Given the results of research conducted in Sobral, the need to investigate the incidence of caries from adolescence to young adulthood became apparent. Therefore, the aim of this study was to investigate the incidence of caries and its determinants in young people in Sobral-CE.

\section{Methodology}

The present research draws on data obtained from an investigation entitled "Health conditions of children in Sobral, CE”, conducted from 1999 to 2000 with children aged five to nine years ${ }^{15}$. On that occasion, 3,425 children were evaluated, resulting in a sub-sample of 1,021 who were assessed with respect to indexes of oral health (dental caries, gingival condition and malocclusions).

Six years later, a new epidemiological study of oral health with longitudinal character which evaluated the incidence of caries and associated factors was conducted. 688 subjects were re-examined, aged 11-15 years ${ }^{16}$. In 2012, the third wave of this study was held, and the following conditions were investigated: dental caries, malocclusion, periodontal disease, tooth loss and trauma.

In the third wave of the cohort, 482 young people were re-examined, with a $70 \%$ response rate compared to the population found in 2006 and $40 \%$ response rate to the population found in 2000. Losses were due to change of address (159), individuals not found at home after three visits (24), refusal to participate (10), incarcerated (8), death (3) and homeless (1). However, this loss was not considered as limiting to the study because the analysis used complete data for the sample of 482 individuals in the cohort. This sample has the power to detect an RR of up to 1.2 with a prevalence of $60 \%$ of the outcome among those not exposed. A reference value of $\alpha=95 \%$ and power (1- $\beta$ ) of $80 \%$ were taken. 
The individuals participating in the study were identified by the community health agent, who scheduled a day so that they could attend the basic health unit closest to their home to perform the research. For those who did not attend on the scheduled date, the research team conducted up to three home visits. In order to search for those who had changed addresses there were visits to schools and factories, and an active search through social networks.

The inter-calibration of the examiners was performed by consensus, with the Kappa index ranging from 0.80 to 0.93 . Examinations occurred under natural light, using a mirror and $\mathrm{WHO}^{17}$ periodontal probe.

For this study we used caries incidence between the second (2006) and third (2012) wave as a dependent variable. The incidence was measured by the experience of new tooth decay by an individual from adolescence to youth. As proposed in Källestal \& Stenlund's study ${ }^{18}$, the incidence was considered positive in situations where the tooth was healthy in 2006 (without decay) and went on to present a situation of "decayed," "restored," "restored with cavity" or "lost to decay" in 2012, or even that the tooth was restored in 2006 and was "decayed," "restored with cavity" or "lost to decay" in 2012.

Socioeconomic conditions and actions and use of oral health services were used as independent variables collected in 2000, 2006 and 2012 by a questionnaire. In the infancy were collected the variables: family income (until/more one minimum wage), education of the household head (until/more 8 years), bathroom at home (yes/no), access to the dentist at least once in their life (yes/ no), time (last year yes/no), cause (routine/pain or treatment) and place of last dental visit (public/private), access denied (yes/no), malnutrition (yes/no) and consumption of school lunch(yes/ no). In adolescence, at the time of the second wave of the study, we used the following variables: family income (until/more one minimum wage), household crowding (until/more 1), student (yes/ no), type school (public/private), access to the dentist at least once in their life (yes/no), time (last year yes/no), cause (routine/pain or treatment) and place of last dental visit (public/private), access denied (yes/no), if they received oral health information (yes/no), participation in collective actions in oral health (yes/no) and tooth brush received in school (yes/no). The variables collected in the third wave (2012) were: gender, race, occupation (employed/unemployed), type of school (public/private), family income (until/ more one minimum wage), household crowding (until/more 1), fluoride water Suply (yes/no), access to the dentist at least once in their life (yes/ no), time (last year yes/no), cause (routine/pain or treatment) and place of last dental visit (public/private), denied access (yes/no) and participation in a group of adolescents (yes/no).

To evaluate the relationship between the independent variables and the incidence of caries from 2006 to 2012, ANOVA and t-test were conducted, along with estimating the relative risk (RR) with their respective confidence interval. This was followed by a Poisson regression model to compose the risk factors for caries incidence, one multiple model was built for each wave. Those variables with a $\mathrm{p}$-value $<0.20$ were included in the multivariate analysis. In the final model only the independent variables were retained that were statistically significant after regression, i.e., $\mathrm{p}<0.05$.

This study was approved by the research ethics committee of the State University of Acaraú Valley with opinion number 1019 and the participants signed an informed consent form ensuring their privacy.

\section{Results}

It was observed that $51.9 \%$ of participants were female and the average age of participants was 17 to 21 years, distributed as follows: 116 were 17 years old, 86 were 18 years, 94 with 19 years, 90 were 20 years, and 96 with 21 years. It was found that $76.8 \%$ studied and/or worked and $23.2 \%$ were unemployed. Of those who studied, most were in public school $(81.7 \%)$, while of those who worked, $58.3 \%$ had formal documented jobs or were civil servants. The reported average family income was $\mathrm{R} \$ 1,037.97$ ( $\mathrm{SD}=810.45)$. 94.6\% reported having access to fluoridated water via the public water Suply.

With regard to the variables of use of dental services, it was found that a small proportion of participants $(7.5 \%)$ never went to the dentist and $24.7 \%$ of young people have had access to dental services denied at least once in life, i.e., for some reason, they could not schedule or conduct a consultation with the dentist. Regarding the time of last dental visit, $50.2 \%$ visited the dentist within the last year, mostly in public service. It was also found that $47.6 \%$ reported that the reason for the last dental visit was for routine maintenance or repair, however, $73 \%$ said they had felt tooth pain sometime in their lives. 
The average incidence of caries between 2006 and 2012 was 2.95 teeth $(S D=2.54)$, with a range from zero to 16 of new decayed teeth. The proportion of youth who showed no incidence of caries was $17.2 \%$. There was no difference in caries incidence between the ages analyzed after ANOVA test $(\mathrm{p}=0.81)$.

During the childhood, not having bathroom at home and have been denied access to the dentist were risk factors for increased incidence of caries. In the adolescence, greater household crowding and have been consulted for reason of pain or treatment were risk factors for increased incidence of caries, while not participated of collective action in oral health and not having consulted a dentist in less than a year were protection factors. With respect to the variables collected in the third wave, it was observed that to attend a public school, have consulted the dentist in last year because of pain or treatment, as well as having been denied access to a dentist at least once in their lives were risk factors for higher incidence of decay (Table 1).

Poisson regression was conducted to verify a model for each one of the waves. Remained as risk factors in the first model (2000), have no toilet at home $[\mathrm{RR}=1.40(95 \% \mathrm{CI} 1.16-1.70)]$ and denied access to the dentist $[\mathrm{RR}=1,36(95 \%$ CI 1.08-1.72)]. Regarding the second follow up, household crowding [RR $=1.17$ (95\% CI 1.01$1.36)]$, dental visit in the last year $[R R=0.78$ (95\% CI 0.70-0.90)] and participation in collective actions $[\mathrm{RR}=0.67$ (95\% CI 0.55-0.81) ] remained as factors related to the incidence of caries in youth. While in the third model, remained type of school [RR $=1.55$ (95\% CI: 1.06 to 2, 26) ] and reason for last consultation $[\mathrm{RR}=1.52(95 \%$ CI: 1.18 to 1.94 )] (Table 2).

\section{Discussion}

It was observed that from adolescence to young adulthood, the average incidence of caries in teeth was 2.95, higher than 1.86 observed from childhood to adolescence in a cohort study conducted in 2006 in the city of Sobral ${ }^{14}$.

Few cohort studies in oral health have been done using the incidence of caries as an outcome. This outcome makes this study relevant as it is possible to detect the appearance of new caries for each tooth throughout life and, consequently, understand the determinants. Using only the DMFT/DMFS as an endpoint to measure the progression of caries in cohort studies implies the loss of sensitivity to detect new cavities, as once a restored tooth has cavities within the cohort, it does not increase the result in the DMFT/DMFS index ${ }^{19}$. Moreover, to consider individuals with the same index value but having different components of DMFT/DMFS is putting individuals with distinct decay at the same level of analysis. Thus, using the incidence of caries allows for identifying the route of dental caries of the individual, and not just the general oral health condition.

As to relevance, it is the only cohort study in Brazilian Northeastern to follow children and adolescents over 12 years with field methodology, which predicted both responses to a questionnaire as the exam of the main dental problems, from primary data. Whereas it is a region with few higher education institutions of excellence, particularly in view of the research, and the lack of specific funding for this type of study, expensive by nature, the viability of the research just materialized by the involvement of several characters linked two federal institutions of higher education (UFRN and UFC-Sobral), in conjunction with the Sobral Department of Health. Perform shifts with teams over more than one year of data collection in place with an annual average temperature of $28^{\circ} \mathrm{C}$ was configured as a challenge every time of the survey, only made possible by the commitment and dedication of actors effectively involved to the prospect of alternatives to improve the oral health of the population of the region.

In this study, it was found that the variables that express the socioeconomic situation (bathroom at home, household crowding and type of school) of the young and during their lives have a statistically significant relationship with the greatest incidence of dental caries. The life course theory states that the accumulation process of experiences of social disadvantage throughout life leads to oral health problems in adulthood, as observed in other studies ${ }^{11,20,21}$ and which was also observed in the present study.

Don't have toilet at home in the childhood, larger household crowding in adolescence, as well as a public school resulted in increased risk to present new cavities. Although there was no relationship found between income and the incidence of caries, such variables (bathroom at home, household crowding and type of school) are considered indicators of social status. Piosevan et al. ${ }^{22}$ claim that type of school is an alternative indicator that expresses the socioeconomic situation in epidemiological studies on oral health in Brazil. 
Table 1. Mean number of teeth with caries incidence according to socioeconomic and actions and use of oral health services in the three waves. Sobral, 2012.

\begin{tabular}{|c|c|c|c|c|}
\hline Variable & $\mathbf{N}$ & Mean (SD) & $\mathrm{RR}(\mathrm{CI})$ & $\mathbf{p}^{*}$ \\
\hline \multicolumn{5}{|c|}{ Variables of childhood (2000) } \\
\hline \multicolumn{5}{|c|}{ Bathroom at home } \\
\hline Yes & 404 & 2.76 & & \\
\hline No & 77 & 3.95 & $1.43(1.19-1.72)$ & $<0.0001$ \\
\hline \multicolumn{5}{|c|}{ Access denied to the dentist } \\
\hline No & 450 & 2.89 & & \\
\hline Yes & 31 & 3.90 & $1.35(1.07-1.70)$ & 0.01 \\
\hline \multicolumn{5}{|l|}{ Malnutrition } \\
\hline Não & 343 & 2.84 & & \\
\hline Sim & 128 & 3.28 & $1.15(0.98-1.36)$ & 0.08 \\
\hline \multicolumn{5}{|c|}{ Variables of adolescence (2006) } \\
\hline \multicolumn{5}{|c|}{ Household crowding } \\
\hline Until 1 & 249 & $2.63(2.28)$ & & \\
\hline+1 & 233 & $3.29(2.76)$ & $1.25(1.07-1.45)$ & 0.004 \\
\hline \multicolumn{5}{|c|}{ Visited the dentist last year } \\
\hline Yes & 227 & $3.30(2.48)$ & & \\
\hline No & 205 & $2.64(2.45)$ & $0.81(0.69-0.94)$ & 0.006 \\
\hline \multicolumn{5}{|c|}{ Reason for last dental visit } \\
\hline Routine & 199 & $2,61(2,48)$ & & \\
\hline Pain/treatment & 234 & $3,29(2,46)$ & $1.26(1.07-1.49)$ & 0.004 \\
\hline \multicolumn{5}{|c|}{ Collective actions in oral health } \\
\hline Yes & 260 & $3.45(2.73)$ & & \\
\hline No & 217 & $2.36(2.17)$ & $0.69(0.59-0.80)$ & $<0.001$ \\
\hline \multicolumn{5}{|c|}{ Received toothbrush at school } \\
\hline Yes & 174 & $3.20(2.47)$ & & \\
\hline No & 304 & $2.83(2.57)$ & $0.88(0.76-1.03)$ & 0.12 \\
\hline \multicolumn{5}{|l|}{ Variables of youth (2012) } \\
\hline \multicolumn{5}{|l|}{ Type of school } \\
\hline Private & 47 & 2.32 & & \\
\hline Public & 210 & 3.19 & $1.38(1.02-1.86)$ & 0.03 \\
\hline \multicolumn{5}{|c|}{ Visited the dentist last year } \\
\hline Yes & 224 & $3.23(2.59)$ & & \\
\hline No & 222 & $2.73(2.42)$ & $0.85(0.72-0.98)$ & 0.03 \\
\hline \multicolumn{5}{|c|}{ Reason for last dental visit } \\
\hline Routine & 212 & $2.46(2.19)$ & & \\
\hline Pain/treatment & 230 & $3.44(2.65)$ & $1.09(1.00-1.18)$ & 0.04 \\
\hline \multicolumn{5}{|c|}{ Access denied to the dentist } \\
\hline Não & 363 & $2.80(2.52)$ & & \\
\hline Sim & 119 & $3.42(2.54)$ & $1.22(1.04-1.43)$ & 0.01 \\
\hline
\end{tabular}

"t test.

Oral health cohort studies from birth developed in New Zealand and Brazil found that the best conditions of a family at child birth and throughout life were associated with better oral health conditions in adolescence and adulthood, as well as better quality of life related to oral health problems ${ }^{11,23-26}$.

For the variables that express the use of dental services, it was noted that the access denied in the childhood, the last dental consultation and participation in collective actions in oral health in adolescence, as well as the reason for the last dental visit were associated with higher incidence of caries.

Study ${ }^{14}$ also found that visiting the dentist in the last twelve months was a risk factor for increased incidence of caries in adolescence. Other authors found that regular visits to the dentist presented itself as a risk factor for increased severity of dental caries among adults ${ }^{27}$, and that 
Table 2. Model adjusted for incidence of caries. Sobral, 2012.

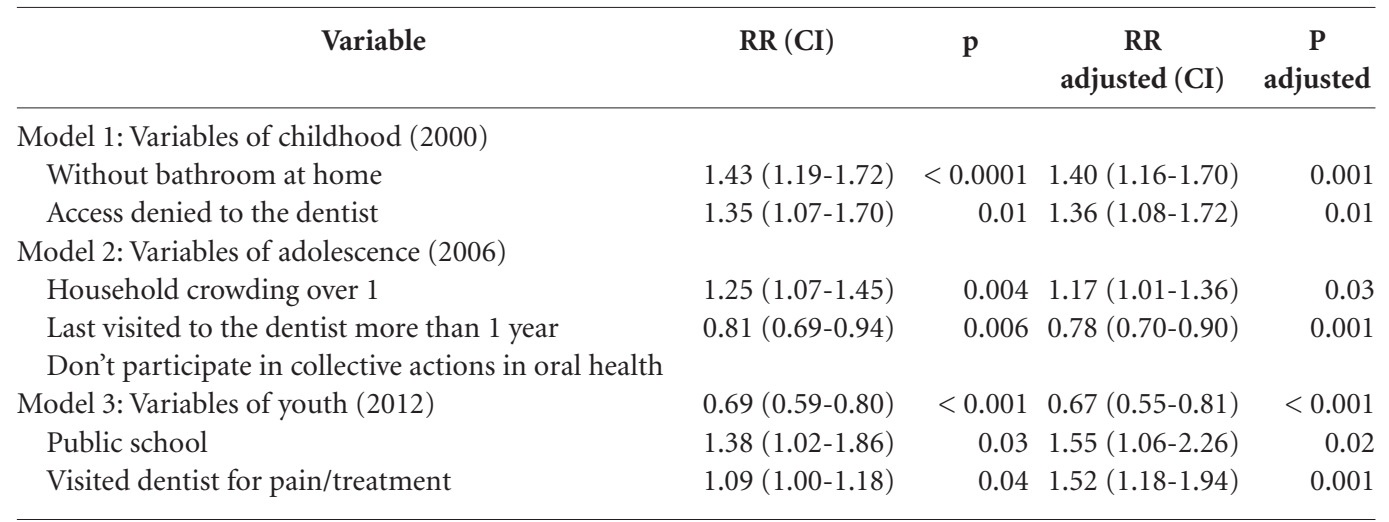

the percentage of cavity-free individuals is higher among those with lower frequency of consulting the dentist ${ }^{28}$.

This is not to understand that the use of the health service is responsible for measures culminating in the increased of incidence, but that the fragmentation of service and the lack of responsibility in caring are related to a way of organizing work and decision-making processes in organizations that contribute to the health professionals reduce their work object (and therefore its clinical responsibility) to procedures, diseases or body parts (rather than take responsibility for people globally $)^{29}$. The fact is that the denied access to dental services in childhood resulted in the accumulation of oral health needs along life course, causing an increased incidence of caries in youth, probably making them seek the service because of pain or treatment.

The epidemiological survey of oral health in a national based study conducted in Brazil revealed that the main reason for visiting a dentist in all age groups was for pain or treatment, then it showed that most people who use dental services in the country are those that have some need for oral health ${ }^{2}$, which suggests the possibility of visiting the dentist in the last twelve months in adolescence is only performed by individuals who have the most need.

Other studies have also identified a higher prevalence of caries in those adolescents who visited the dentist because of pain or restoration when compared with those who visited the dentist because of prevention, as observed in this study ${ }^{30-32}$. In the cohort study developed in New Zealand, it was found that those individuals who only visit the dentist when dental problem appear had worse impact of oral health on daily living and quality of life ${ }^{24}$.
With respect to participation in collective actions in oral health in adolescence such as topical fluoride application, whether as a mouthwash or gel, and supervised oral hygiene introduced itself as a risk factor for increased incidence of caries in youth, a fact that should be analyzed with caution given the vast literature concerning the preventive effect of the methods of fluoride. These findings could be related to bias of information regarding the real understanding on what would be particularly collective actions in oral health itself from the interviewed. This is quite often confused even by health professionals to perform these actions within the $\operatorname{clinic}^{33}$. Furthermore, this finding indicates the need to reassess the protocols of collective action on oral health in the city.

Deny access to the dentist during infancy implies accumulation of oral health needs throughout life, this reveals a critical period for oral health in youth. It is important to identify "windows of opportunity", considered the period of life in which the risk for the disease is higher and when interventions may have greater long-term benefits for the promotion of oral health and reduce inequalities ${ }^{34,35}$. Protect children from the effects of socioeconomic adversity could reduce the burden of disease experienced by adults ${ }^{11}$. Then, it is necessary to increase the access to oral health care during childhood, especially actions of promotion and prevention.

A limitation of this study refers to very large interval between waves, six years, where other events related to oral health and the socioeconomic trajectory could have occurred and were not identified in the waves of the cohort, and hinder the monitoring of individuals, which can lead to selection biases. It should also be noted that the lack of external financing greatly hindered the possibility of obtaining other sources of informa- 
tion to access the participants of the study, which contributed to losses along the third wave.

This study revealed that the use of services and oral health actions during the adolescence and youth have not been sufficient to reduce inequities in oral health. When health services are organized in a universal and equitable form, they try to compensate, at least in part, the damaging results of the social inequalities to groups most vulnerable ${ }^{7}$.

There is therefore a challenge approach not only as dental locus service, but as the responsible for health care population, incorporating the broad concepts of health promotion ${ }^{36}$ and ap- propriating active methodologies in educational guidelines $^{37}$ aimed empowerment of the population. For this it is essential that higher education institutions effectively focus the training to develop skills and abilities in health care, lifelong learning and communication ${ }^{38}$.

Thus, it is important that managers reorganize oral health services in order to proceed mainly on equity of attention thereby reducing oral health inequities. Finally, it was found that greater social deprivation throughout life indicates a higher incidence of dental caries among adults and youth.

\section{Collaborations}

AKM Teixeira participated in all stages of manuscript, AG Roncalli and LRA Noro attended the study design, analysis and interpretation data and critical review.

\section{References}

1. Brasil. Ministério da Saúde (MS). Secretaria de Atenção à Saúde. Departamento de Atenção Básica. Projeto SB Brasil 2003: condições de saúde bucal da população brasileira 2002-2003: resultados principais. Brasília: MS; 2004.

2. Brasil. Ministério da Saúde (MS). Secretaria de Atenção à Saúde. Departamento de Atenção Básica. SB Brasil 2010: Pesquisa Nacional de Saúde Bucal: Resultados principais. Brasília: MS; 2011.

3. Narvai PC, Frazão P, Roncalli AG, Antunes JL. Dental caries in Brazil: decline, polarization, inequality and social exclusion. Rev Panam Salud Pública 2006; 19(6):385-393.

4. Peres SHCS, Carvalho SF, Carvalho CP, Bastos JR, Lauris JR. Polarization of dental caries in teen-agers in the southwest of the State of São Paulo, Brazil. Cien Saude Colet 2008; 13(2):2155-2162.

5. Braveman PA, Kumanyika S, Fielding J, LaVeist T, Borrell LN, Manderscheid R, Troutman A. Health disparities and health equity: the issue is justice. Am J Public Health 2011; 101(Supl. 1):S149-S155.

6. Krieger N. Proximal, distal, and the politics of causation: what's level got to do with it? Am J Public Health 2008; 98(2):221-230.

7. Barata RB. Como e por que as desigualdades sociais $\mathrm{fa}$ zem mal à saúde. Rio de Janeiro: Ed. Fiocruz; 2009.

8. Lynch J, Smith GD. A life course approach to chronic disease epidemiology. Annu. Rev. Public Health 2005; 26:1-35.

9. Peres KG, Peres MA, Araujo CLP, Menezes AMB, Hallal PC. Social and dental status along the life course and oral health impacts in adolescents: a population-based birth cohort. Health Qual Life Outcomes 2009; 7:95. 
10. Peres MA, Barros AJ, Peres KG, Araujo CLP, Menezes AMB, Hallal PC, Victora CG. Oral health follow-up studies in the 1993 Pelotas (Brazil) birth cohort study: methodology and principal results. Cad Saude Publica 2010; 26(10):1990-1999.

11. Thomson WM. Social inequality in oral health. Community Dent Oral Epidemiol 2012; 40(Supl. 2):28-32.

12. Alm A, Wendt LK, Koch G, Birkhed D, Nilsson M. Caries in adolescence - influence from early childhood. Community Dent Oral Epidemiol 2012; 40(2):125-133.

13. Noro LRA, Oliveira AGRC, Mendes Júnior FIR, Lima KC. Children oral health status from Sobral-Ceará. Stoma 2008; 88:29-34.

14. Noro LRA, Oliveira AGRC, Mendes Júnior FIR, Lima KC. Dental caries incidence in adolescents in a city Northeast Brazil, 2006. Cad Saude Publica 2009; 25(4):783-790.

15. Barreto ICHAC, Grisi SJFE. Reported morbidity and its conditionings in children 5 to 9 years old in Sobral, CE, Brazil. Rev. Bras. Epidemiol 2010; 13(1):35-48.

16. Noro LRA, Oliveira AGRC, Mendes Júnior FIR, Lima KC, Teixeira AKM. Toothache and social and economic conditions among adolescents in Northeastern Brazil. Cien Saude Colet 2014; 19(1):105-113.

17. Brasil. Ministério da Saúde (MS). Coordenação Nacional de Saúde Bucal. SB Brasil 2010 - Pesquisa Nacional de Saúde Bucal: Manual da equipe de campo. Brasília: MS; 2009.

18. Källestal C, Stenlund H. Different analytical approaches in an experimental cohort study on preventive measures for caries in adolescents: a comparison between incidence density and increment analysis. Caries Res 2003; 37(1):44-50

19. Page LAF, Thomson WM. Dental caries in Taranaki adolescents: a cohort study. New Zealand Dental Journal 2011; 107(3):91-96.

20. Nicolau B, Thomson WM, Steele JG, Allison PJ. Lifecourse epidemiology: concepts and theoretical models with particular reference to oral chronic conditions. Community Dent Oral Epidemiol 2007; 35(4):241-249.

21. Blas E, Kurup AS, editors. Priority public health conditions knowledge network of the Commission on Social Determinants of Health. Equity, social determinants and public health programmes. Geneva: World Health Organization. 2010.

22. Piovesan C, Pádua MC, Ardenghi TM, Mendes FM, Bonini GC. Can type of school be used as an alternative indicator of socioeconomic status in dental caries studies? A cross-sectional study. BMC Med Res Methodol 2011; 11:37.

23. Peres MA, Peres KG, Barros AJ, Victora CG. The relation between family socioeconomic trajectories from childhood to adolescence and dental caries and associated oral behaviours. J Epidemiol Community Health 2007; 61(2):141-145.

24. Lawrence HP, Thomson WM, Broadben JM, Poulton R. Oral health-related quality of life in a birth cohort of 32-year olds. Community Dent Oral Epidemiol 2008; 36(4):305-316

25. Peres KG, Peres MA, Demcarco FF, Tarquínio SB, Horta BL, Gigante DP. Oral health studies in the 1982 Pelotas (Brazil) birth cohort: methodology and principal results at 15 and 24 years of age. Cad Saude Publica 2011; 27(8):1569-1580.
26. Peres MA, Peres KG, Thomson WM, Broadbent JM, Gigante DP, Horta BL. The influence of family income trajectories from birth to adulthood on adult oral health: findings from the 1982 Pelotas birth cohort. Am J Public Health 2011; 101(4):730-736.

27. Costa SM, Vasconcelos M, Abreu MHNG. High dental caries among adults aged 35 to 44 years: case-control study of distal and proximal factors. Int J Environ Res Public Health 2013; 10(6):2401-2411.

28. Moysés SJ. Oral health and healthy cities: an analysis of intra-urban differentials in oral health outcomes in relation to "health cities" policies in Curitiba, Brazil [thesis]. London: University College London; 2000.

29. Cunha GT, Campos GWS. Matrix Support and Primary Health Care. Saude Soc 2011; 20(4):961-970.

30. Nicolau B, Marcenes W, Bartley M, Sheiham A. A life course approach to assessing causes of dental caries experience: the relationship between biological, behavioral, socio-economic and psychological conditions and caries in adolescents. Caries Res 2003; 37(5):319326.

31. Vadiakas G, Oulis CJ, Tsinidouk K, Mamai-Homata E, Polychronopoulou A. Social-behavioral factors influencing oral health of 12 and 15 year old Greek adolescents. A national pathfinder survey. Eur Arch Paediatr Dent 2011; 12(3):139-145.

32. Cypriano S, Hugo FN, Sciamarelli MC, Tôrres LH, Sousa MDA L, Wada RS. Factors associated with the incidence of dental caries among schoolchildren living in a municipality with low prevalence of dental caries. Cien Saude Colet 2011; 16(10):4095-4106.

33. Almeida GCM, Ferreira MAF. Oral health in the context of the Family Health Program: preventive practices targeting individual and public health. Cad Saude Publica 2008; 24(9):2131-2140.

34. Watt RG. Emerging theories into the social determinants of health: implications for oral health promotion Community Dent Oral Epidemiol 2002; 30(4):241-247.

35. Broadbent JM, Thomson WM, Poulton R. Progression of dental caries and tooth loss between the third and fourth decades of life: a birth cohort study. Caries Res 2006; 40(6):459-465.

36. Haikal DSA, Martins AMEBL, Aguiar PHS, Silveira MF, Paula AMB, Ferreira EF. Access to information on oral hygiene and tooth loss due to caries among adults. Cien Saude Colet 2014; 19(1):287-300.

37. Santos A, Nadanovsky P, Oliveira BH. Inconsistencies in recommendations on oral hygiene practices for children by professional dental and paediatric organizations in ten countries. Int J Paediatr Dent 2011; 21(3):223-231.

38. Costa ICC, Araújo MNT. Definition of abilities profile in public health based on the experience of dentists of public service. Cien Saude Colet 2011; 16(Supl. 1):11811189.

Artigo apresentado em 17/04/2015

Aprovado em 02/09/2015

Versão final apresentada em 04/09/2015 